\title{
Preparation and Physicochemical Properties of Functionalized Silica/Octamethacryl-Silsesquioxane Hybrid Systems
}

\author{
Karolina Szwarc-Rzepka, Filip Ciesielczyk, and Teofil Jesionowski \\ Institute of Chemical Technology and Engineering, Faculty of Chemical Technology, Poznan University of Technology, \\ M. Sklodowskiej-Curie 2, 60965 Poznan, Poland \\ Correspondence should be addressed to Teofil Jesionowski; teofil.jesionowski@put.poznan.pl
}

Received 28 January 2013; Revised 5 April 2013; Accepted 14 April 2013

Academic Editor: Yanbao Zhao

Copyright (C) 2013 Karolina Szwarc-Rzepka et al. This is an open access article distributed under the Creative Commons Attribution License, which permits unrestricted use, distribution, and reproduction in any medium, provided the original work is properly cited.

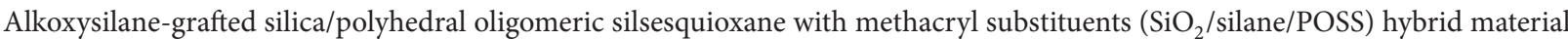
was synthesized according to hydrolyzation and condensation reactions in the so-called "bifunctionalization process." It is a new attractive system because of its physicochemical, especially thermal and structural, properties. This innovative method of preparation as well as specific physicochemical and useful properties determine the potential applications of such products in many industries. The structure and physicochemical parameters of obtained hybrid systems were characterized using infrared spectroscopy (FTIR), ${ }^{13} \mathrm{C}$ and ${ }^{29} \mathrm{Si}$ solid-state nuclear magnetic resonance (CP MAS NMR), and thermal analysis. The mechanism of bifunctionalization reaction was proposed. The chemical immobilization of silane coupling agent and Methacryl POSS onto silica support surface was noted during the study. Those changes caused a significant increase in the hydrophobic character of fillers obtained. Moreover, changes in thermal stability of $\mathrm{SiO}_{2} /$ silane/POSS hybrid systems in comparison to pure POSS modifier were also observed.
\end{abstract}

\section{Introduction}

Polyhedral oligomeric silsesquioxanes have recently become the focus of much attention. This is a group of well-developed, symmetrical molecules characterized by small particle sizes (lower than $100 \mathrm{~nm}$ ). In the present research investigations, the most common forms of POSS compounds are cubic $\mathrm{R}_{8} \mathrm{Si}_{8} \mathrm{O}_{12}$, the so-called $\mathrm{T}_{8}$ structures, consisting of cages with total number of silicon atoms $(n)$ equal to 8 . The organic substituents $\mathrm{R}$, with reactive functional groups compatible with (e.g.) a polymer, are attached to the inorganic fragment of each vertex of a silsesquioxane cage containing $\mathrm{Si}-\mathrm{O}-\mathrm{Si}$ groups [1-3]. As regards polymer processing, the most popular are POSS compounds with amino, vinyl, epoxy, and methacrylate reactive groups [4-8]. Silsesquioxanes with methacrylate groups are well described in the existing literature. Polyhedral oligomeric silsesquioxanes containing reactive methacrylate groups are mainly used as fillers of polymer matrixes [9-13] or in the preparation of dental materials $[14,15]$. In the previous research articles, Methacryl POSS was used as a polymer filler acting as a cross-linking agent to the polymer or as an agent increasing the rate of the polymerization process. Changes in conversion degree increase were also noted [16]. Introduction of oligomeric silsesquioxane to elastomer compounds does not always produce the desired results, such as improvement of mechanical parameters, which to some extent limits the possibility of replacing traditional fillers with POSS.

Experiments conducted with Polyhedral oligomeric silsesquioxanes seem very promising, although POSS compounds are still considered as a luxury and requiring nanofillers. For this reason, it was decided to combine the innovation and attractiveness of POSS with the functionality of traditional fillers such as silica. Attempts were made to obtain a new group of highly functional hybrid fillers. This type of material is economically interesting because of the possibility of covering a relatively cheap and easily obtainable filler [17-19] with a thin layer of expensive material [20]. The described modification process reduces the costs associated with the more expensive materials through the use of a commonly available cheap filler. The properties of the materials obtained, especially chemical stability, thermal 
and/or mechanical strength, were maintained or improved. A bifunctionalization process has been used by, among others, Carniato et al. [21]. The authors described the immobilization process of Ti-POSS compound onto a surface of ordered, mesoporous silica (SBA-15) and silica with unordered structure $\left(\mathrm{SiO}_{2}\right.$-Dav). The final product (Ti-POSS-TSIPI) resulted from covalent bonding of monoaminosubstituted POSS with 3-isocyanatopropyltriethoxysilane in alkaline $\mathrm{pH}$. The hybrid systems obtained were used as catalysts in the reaction of epoxidation of limonene. Another interesting example of a bifunctionalization process was presented by Bhagiyalakshmi et al. [22]. A chlorofunctionalized mesoporous silica (SBA-15) surface was additionally grafted with octa(3-aminophenyl)octasilsesquioxane (OAPS). The ClSAB-15/OAPS systems obtained via the proposed mechanism were characterized by high heat resistance, which was used in a further research concerning the adsorption of $\mathrm{CO}_{2}$. Functionalized hybrid systems of silica/polyhedral oligomeric silsesquioxanes ( $\mathrm{SiO}_{2} /$ POSS) were also prepared by a mechanical method [23], using spherical and hydrated silicas precipitated in an emulsion or water system. Monoand octasubstituted silsesquioxanes were used as silica surface modifying agents. The proposed mechanical method made it possible to obtain products with well-defined dispersive properties. Moreover, the products obtained had higher hydrophobicity, which is important for applications in polymer processing.

The possibility of bifunctionalization of an inorganic filler surface with alkoxysilanes and POSS compounds helps to increase their range of application, while also improving the mechanical properties of the polymer composites and reducing the costs of their production. All of these factors confirm the appropriateness of the ongoing research and further development of technology for next-generation hybrid filler production, especially since the number of existing reports on the surface bifunctionalization of inorganic supports using POSS compounds is quite small, and most of them appeared in the last decade.

\section{Experimental Section}

2.1. Materials. Hydrated silica was obtained in the process of precipitation from aqueous solutions of sodium silicate and sulfuric acid, as it was described earlier [24]. This inorganic filler surface was grafted with selected alkoxysilanes-see Table 1 (purchased from Sigma-Aldrich) and also Methacryl POSS Cage Mixture-see Table 2 (purchased from Hybrid Plastics Co.) in the amounts of 3,5 , or 10 weight parts by mass of $\mathrm{SiO}_{2}$.

2.2. Bifunctionalization of Silica Surface. Modification of hydrated silica was performed by the hydrolysis and condensation method using selected alkoxysilanes and Methacryl POSS compound. Silane coupling agents were at first hydrolyzed in the methanol/water environment (4/1 v/v) and then sprayed directly onto the surface of silica. The silane coupling agents were used in the amounts of 3,5, or 10 weight parts by mass. After deposition of a proper amount of the modifier on the $\mathrm{SiO}_{2}$ surface, the solvent was distilled off and the sample was dried by a convection at $105^{\circ} \mathrm{C}$ for 1 hour. Removal of the solvent (methanol) was realized in a vacuum evaporator (made by Büchi Labortechnik $\mathrm{GmbH}$ ) working under 337 mbar pressure and at $60^{\circ} \mathrm{C}$-temperature of water bath. On the so prepared, functionalized filler, the Methacryl POSS Cage Mixture was deposited in an analogous way. POSS modifier, in the amounts of 3, 5, or 10 weight parts, prepared in the toluene solution, was introduced directly onto the surface of silanized silica. After deposition, the solvent was distilled off (pressure: 76 mbar, water bath temperature: $60^{\circ} \mathrm{C}$ ) and the sample was drying by convection at $120^{\circ} \mathrm{C}$ for 48 hours. The proposed scheme of preparation of bifunctionalized $\mathrm{SiO}_{2}$ is shown in Figure 1 .

On the surface of silica filler modified with the selected organosilane and POSS compound, a reaction of condensation takes place between the functional groups of the silane and POSS and the silanol groups from the inorganic support; see Figure 2.

2.3. Evaluation of Physicochemical Properties. Determination of certain physicochemical parameters was undertaken to verify the effectiveness of silica surface modification with selected organosilanes and POSS compound.

Fourier transform infrared spectroscopy (FTIR) measurements were conducted on an IFS 66v/S spectrophotometer (Bruker) at room temperature. The sample was prepared by mixing with $\mathrm{KBr}$ and then pressed into small flakes. FTIR spectra were obtained in the transmission mode between 4000 and $400 \mathrm{~cm}^{-1}$.

${ }^{29} \mathrm{Si}$ NMR and ${ }^{13} \mathrm{C}$ CP MAS NMR measurements were carried out on a DSX spectrometer (Bruker). For the determination of NMR spectra, a sample of about $100 \mathrm{mg}$ was placed in a $\mathrm{ZrO}_{2}$ rotator with diameter $4 \mathrm{~mm}$, which enabled spinning of the sample. Centrifugation at the magic angle was performed at a spinning frequency of $8 \mathrm{kHz} .{ }^{29} \mathrm{Si} \mathrm{CP}$ MAS NMR spectra were recorded at pulse duration $4.5 \mu \mathrm{s}$, contact time $1.5 \mathrm{~ms}$, and pulse spacing $6 \mathrm{~s}$. The ${ }^{13} \mathrm{C} \mathrm{CP} \mathrm{MAS}$ NMR spectra were recorded at $100.63 \mathrm{MHz}$ in a standard $4 \mathrm{~mm}$ MAS probe using a single pulse excitation with high power proton decoupling (pulse repetition $10 \mathrm{~s}$, spinning speed $8 \mathrm{kHz}$ ).

The chemical composition of the functionalized $\mathrm{SiO}_{2}$ systems was determined using a Vario EL Cube apparatus (Elementar Analysensysteme $\mathrm{GmbH}$ ). A $25 \mathrm{mg}$ portion of the sample was placed in an 80-position autosampler. The sample was placed in a system in which it was combusted in an oxygen atmosphere. After passing through appropriate catalysts in a helium stream, the resulting gases were separated in an adsorption columns and then recorded using a detector. The results are given to $\pm 0.001 \%$, and each is obtained by averaging three measurements.

The surface area $S_{\mathrm{BET}}$ (calculated from the BET equation) was measured by low-temperature adsorption of nitrogen. The isotherms of nitrogen adsorption/desorption were measured at $77 \mathrm{~K}$ using an ASAP 2020 apparatus (Micromeritics Instrument Co.). On the basis of the isotherms, BET-specific surface area $\left(S_{\mathrm{BET}}\right)$ was calculated, and the pore size $\left(D_{P}\right)$ and volume $\left(V_{P}\right)$ were found from the BJH equation (BarrettJoyner-Halenda). With regard to the high accuracy of the 
TABLE 1: Alkoxysilanes used for inorganic filler surface functionalization.

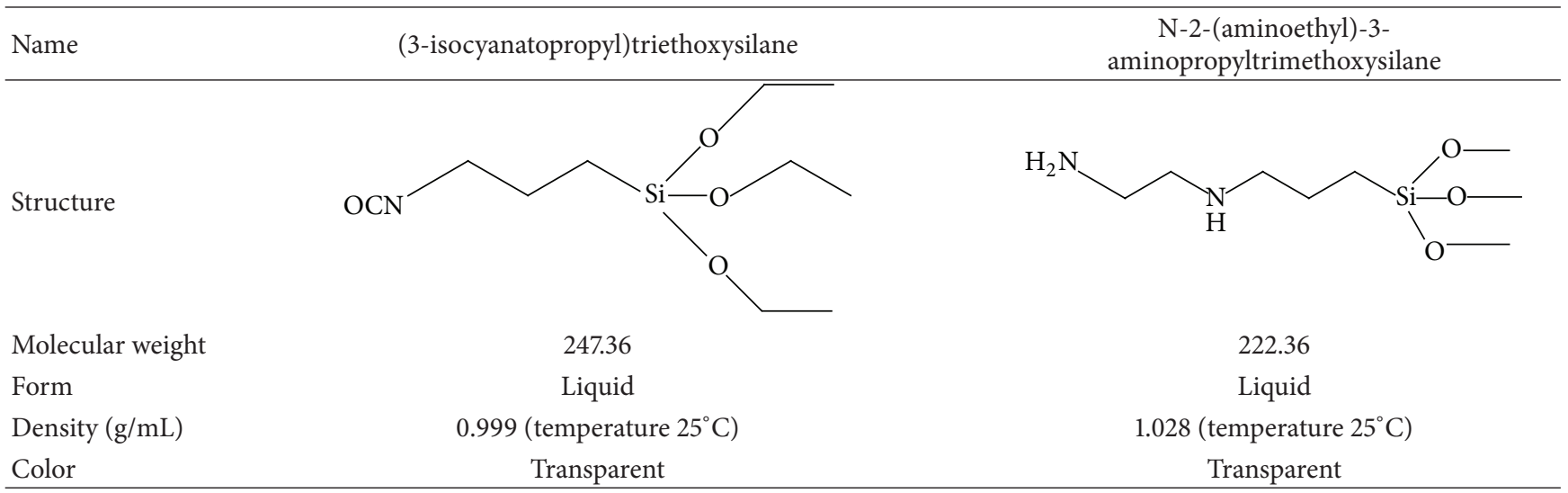

TABLE 2: POSS compound used to inorganic filler surface functionalization.

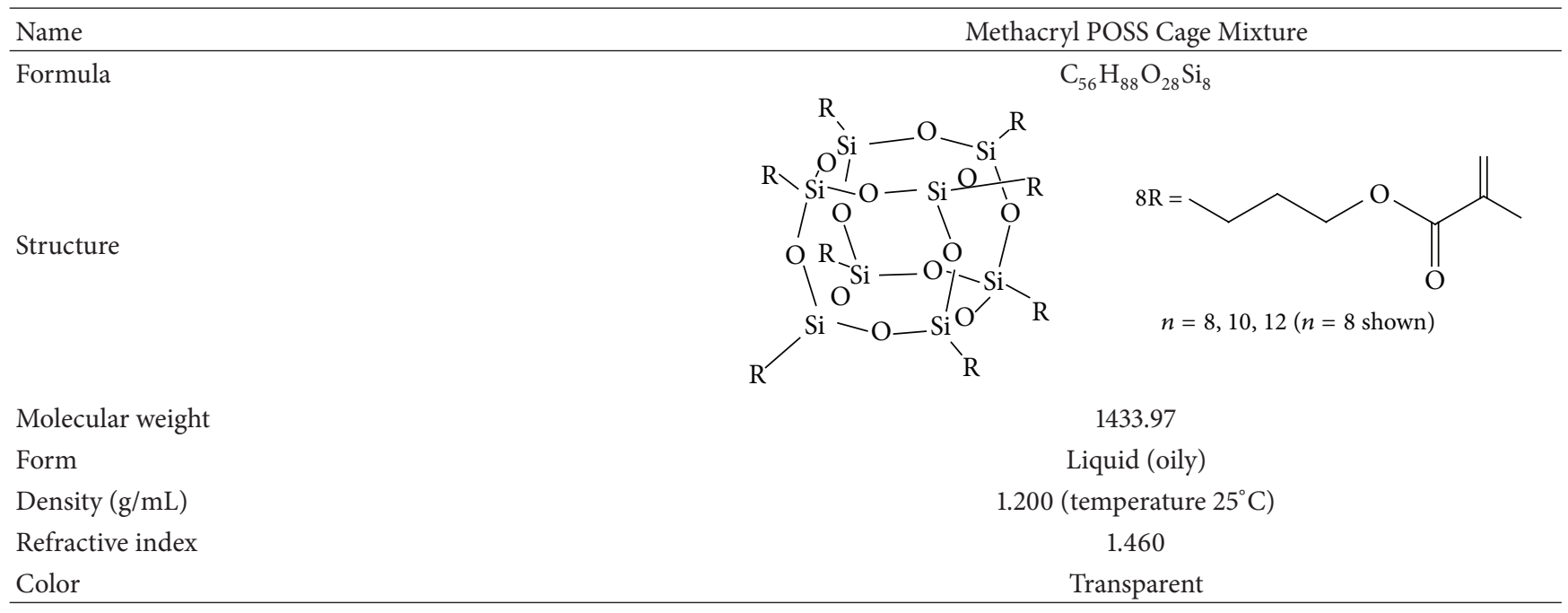

instrument used $\left( \pm 0.0001 \mathrm{~m}^{2} / \mathrm{g}\right)$, the surface area values were rounded up to whole numbers and the mean pore size $\left(D_{P}\right)$ and total pore volume $\left(V_{P}\right)$ to whole numbers and two decimal places, respectively.

Dispersive characteristics of unmodified and bifunctionalized silica nanocomposites were determined by an apparatus Zetasizer Nano ZS and Mastersizer 2000, both made by Malvern Instruments Ltd., operating on the noninvasive back scattering method and laser diffraction method measuring particles of the sizes from 0.6 to $6000 \mathrm{~nm}$ and from 0.2 to $2000 \mu \mathrm{m}$, respectively. Measurements of particle size were at least ten times repeated for each sample.

The morphology and microstructure of the hybrids obtained were analyzed using a Jeol 1200 EX II transmission electron microscope, at an accelerating voltage of $80 \mathrm{kV}$, and Zeiss EVO40 scanning electron microscope.

Thermogravimetric analysis was performed using a Jupiter STA 449 F3 (Netzsch GmbH). Samples weighing approximately $10 \mathrm{mg}$ were placed in an $\mathrm{Al}_{2} \mathrm{O}_{3}$ crucible and heated at a rate of $10^{\circ} \mathrm{C} / \mathrm{min}$ from 30 to $1000^{\circ} \mathrm{C}$ in a nitrogen atmosphere, at a flow rate of $40 \mathrm{~cm}^{3} / \mathrm{min}$.
To evaluate the hydrophilic/hydrophobic surface character of the fillers obtained, the wettability profiles with water were estimated Tensiometer K100 equipped with appropriate software (Krüss $\mathrm{GmbH}$ ). The measurements were conducted over an equal time period, until a stable sample mass value was obtained (approx. $10 \mathrm{~min}$; the mass was $0.4 \mathrm{~g}$ ).

\section{Results and Discussion}

3.1. FTIR and ${ }^{29} \mathrm{Si},{ }^{13} \mathrm{C} C P$ MAS NMR Analysis. Figure 3 shows the FTIR spectra of hydrated silica (sample 0), the hybrids obtained after silica modification with 5 weight parts by mass of isocyanate silane and 10 weight parts by mass of POSS compound (sample 6C), and 5 weight parts by mass of aminosilane and 10 weight parts by mass of POSS compound (sample 6D). The spectra presented prove a high efficiency of modification and change in the chemical character of the $\mathrm{SiO}_{2}$ surface.

Spectrum for sample 0 (hydrated silica) presents two characteristic absorption bands at 1100 and $595 \mathrm{~cm}^{-1}$, which 

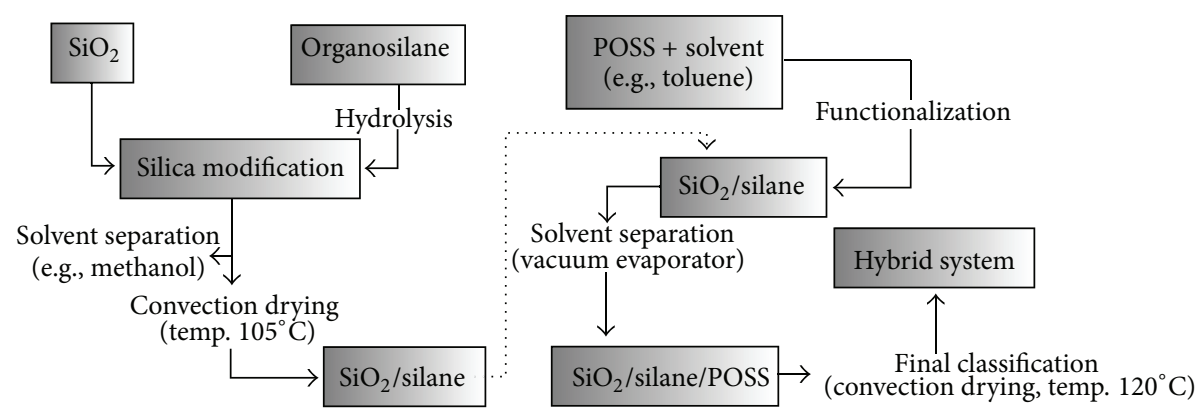

FIGURE 1: Preparation of bifunctionalized $\mathrm{SiO}_{2}$-based hybrid.

are assigned to $\mathrm{Si}-\mathrm{O}-\mathrm{Si}$ stretching and bending vibration, respectively. The spectrum of unmodified silica also shows absorption peak around $1640 \mathrm{~cm}^{-1}$, which is assigned to the bending mode of physically absorbed water molecules, analogy to [25]. By the way, the intensity of the band at 3600$3200 \mathrm{~cm}^{-1}$ was assigned to the stretching vibrations of $-\mathrm{OH}$ groups coming from physically absorbed water.

The spectra of bifunctionalized samples (6C and 6D) were observed to reduce the intensity of absorption bands assigned to $-\mathrm{OH}$ groups in the range of $3600-3200 \mathrm{~cm}^{-1}$. Reduction of the intensity of this band confirms a chemical bonding of the modifier to silica surface and effective substitution of double vicinal groups by its molecules. In the same range (3600$3200 \mathrm{~cm}^{-1}$ ), the band assigned to stretching vibrations of $\mathrm{NH}$ groups was also found, but it is effectively masked by the band assigned to silanol groups. The band at $1720 \mathrm{~cm}^{-1}$ arises from the carbonyl stretching vibrations $(\nu(=\mathrm{C}=\mathrm{O}))$. This situation was especially observed for the hybrid modified with isocyanate silane (sample 6C). The presence of a weak absorption band at $1550 \mathrm{~cm}^{-1}$, probably related with the appearing of $v(\mathrm{C}=\mathrm{C})$, also has to be mentioned. Besides, the spectrum of hybrids produced contains the stretching vibration band $\nu(\mathrm{C}-\mathrm{H})$ in the range of $2900-2850 \mathrm{~cm}^{-1}$. For the verification of the proposed mechanism of $\mathrm{SiO}_{2} /$ silane interactions, the FTIR spectrum of silica grafted with (3isocyanatopropyl)triethoxysilane (Figures 3(c), and 3(d)) was also obtained. The presence of an absorption band around $1640 \mathrm{~cm}^{-1}$ was noted, attributed to the bending mode of physically absorbed molecules of $\mathrm{H}_{2} \mathrm{O}$, as well as a clear absorption band at $1695 \mathrm{~cm}^{-1}$, attributed to bending vibrations of the $\mathrm{N}-\mathrm{H}$ group related to the primary amine created in the hydrolysis reaction (in a methanol/water system).

${ }^{29} \mathrm{Si}$ and ${ }^{13} \mathrm{C}$ CP MAS NMR spectra of hydrated silica (sample 0 ) and silica modified with 5 weight parts by mass of aminosilane and 5 weight parts by mass of POSS compound (Sample 5D) are presented in Figures 4 and 5.

The ${ }^{29}$ Si CP MAS NMR spectrum of the unmodified hydrated silica shows two signals at $-100,-110 \mathrm{ppm}$. The main signal at $-100 \mathrm{ppm}$ is assigned to a structure of three siloxane groups and one silanol group-isolated silanols $\left(Q_{3}\right)$, while the signal at $-110 \mathrm{ppm}$ - to four siloxane bridges $\left(\mathrm{Q}_{4}\right)$. After silica surface treatment with N-2-(aminoethyl)3-aminopropyltrimethoxysilane and Methacryl POSS, the Q signals decreased. This could be caused by the reaction of the modifiers with the surface silanol groups.

This reaction will also result in the loss of $\equiv \mathrm{Si}-\mathrm{OH}$ groups and the formation of $\equiv \mathrm{Si}-\mathrm{O}-\mathrm{Si} \equiv$ linkages, which is demonstrated by the change in the intensity of the $\mathrm{Q}$ signals indicated in the ${ }^{29} \mathrm{Si}$ CP MAS NMR spectrum. In the spectrum of silica after modification process, $\mathrm{T}^{2}(-67 \mathrm{ppm})$ and $\mathrm{T}^{3}(-73 \mathrm{ppm})$ structures appeared analogical as described by Whitnall et al. [26], informing about the condensation of alkoxy and functional groups of a given modifier to the silica matrix, respectively, particularly well visible for sample 5Dmodified with 5 weight parts by mass of aminosilane and 5 weight parts by mass of Methacryl POSS. This is the evidence of the chemisorption of the modifiers applied and a proof of effective modification. Another proof of the chemisorption of the modifiers is given by the ${ }^{13} \mathrm{C}$ CP MAS NMR spectrum presented in Figure 5.

The range between $8 \mathrm{ppm}$ and $21 \mathrm{ppm}$ derives from the $\mathrm{CH}_{2}-$ groups, while that at $37 \mathrm{ppm}$ to $-\mathrm{CH}_{3}$ groups from the mixture of modifiers used. The signals appearing at $50 \mathrm{ppm}$ are assigned to $\equiv \mathrm{C}-\mathrm{N}$ = groups, coming from carbon, occurring in the secondary amine, while the signal appearing at $65 \mathrm{ppm}$ is assigned to the $\equiv \mathrm{C}-\mathrm{C} \equiv$. Moreover, the signal at $112 \mathrm{ppm}$ assigned to the $=\mathrm{C}=\mathrm{CH}_{2}$ group was observed, which unfortunately has been masked and is not observed on the FTIR spectra. The last signal appearing at $173 \mathrm{ppm}$ is assigned to $=\mathrm{C}=\mathrm{O}$ groups, derived from the POSS structure.

3.2. Elemental Analysis of Hybrid Systems Obtained. In the next stage of the study, the chemical composition of received fillers was evaluated using elemental analysis (Figure 6 and Table 3). This analysis was performed to verify the effectiveness of the modification process performed and to estimate the degree of inorganic support surface coverage with selected modifying agents. The silica surface coverage degree was calculated according to Berendsen and de Golan equation [27].

Analysis of experimental data has shown the percentage increase in the content of carbon, nitrogen, and hydrogen together with increasing amount of silane coupling agents and Methacryl POSS compound used in the functionalization process of $\mathrm{SiO}_{2}$, which also determines the increase in the degree of support coverage $(P)$. 


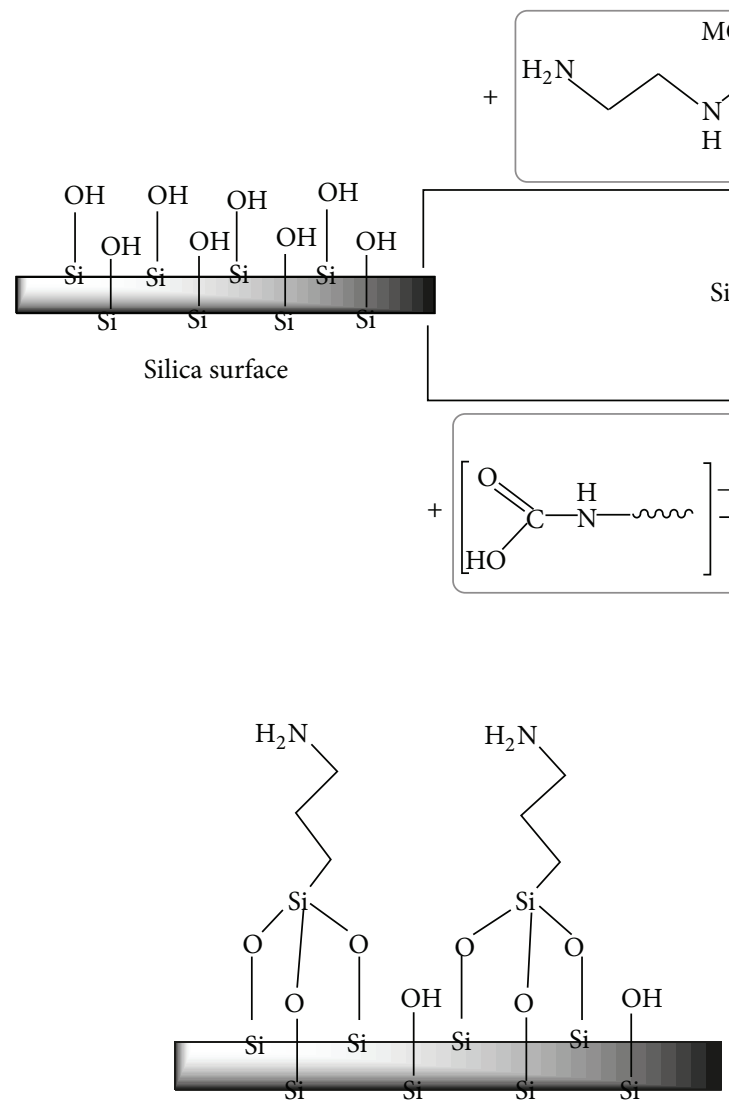

Silane modified silica surface

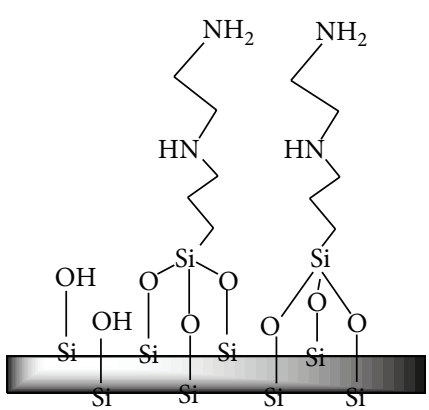

Silane modified silica surface

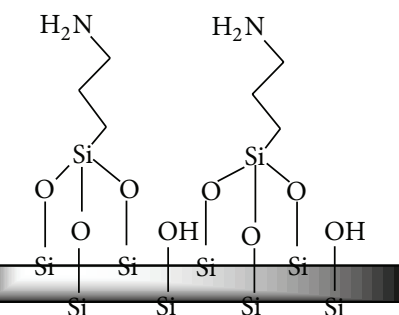

(a)

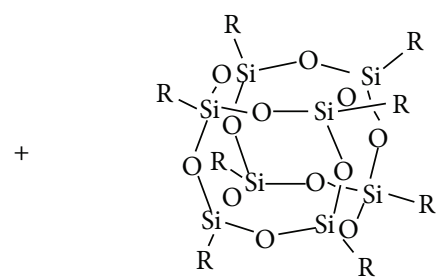

POSS compound

$8 \mathrm{R}=\mathrm{CH}_{2}=\mathrm{C}\left(\mathrm{CH}_{2}\right) \mathrm{COOC}_{3} \mathrm{H}_{7}$

$n=8,10,12(n=8$ shown $)$
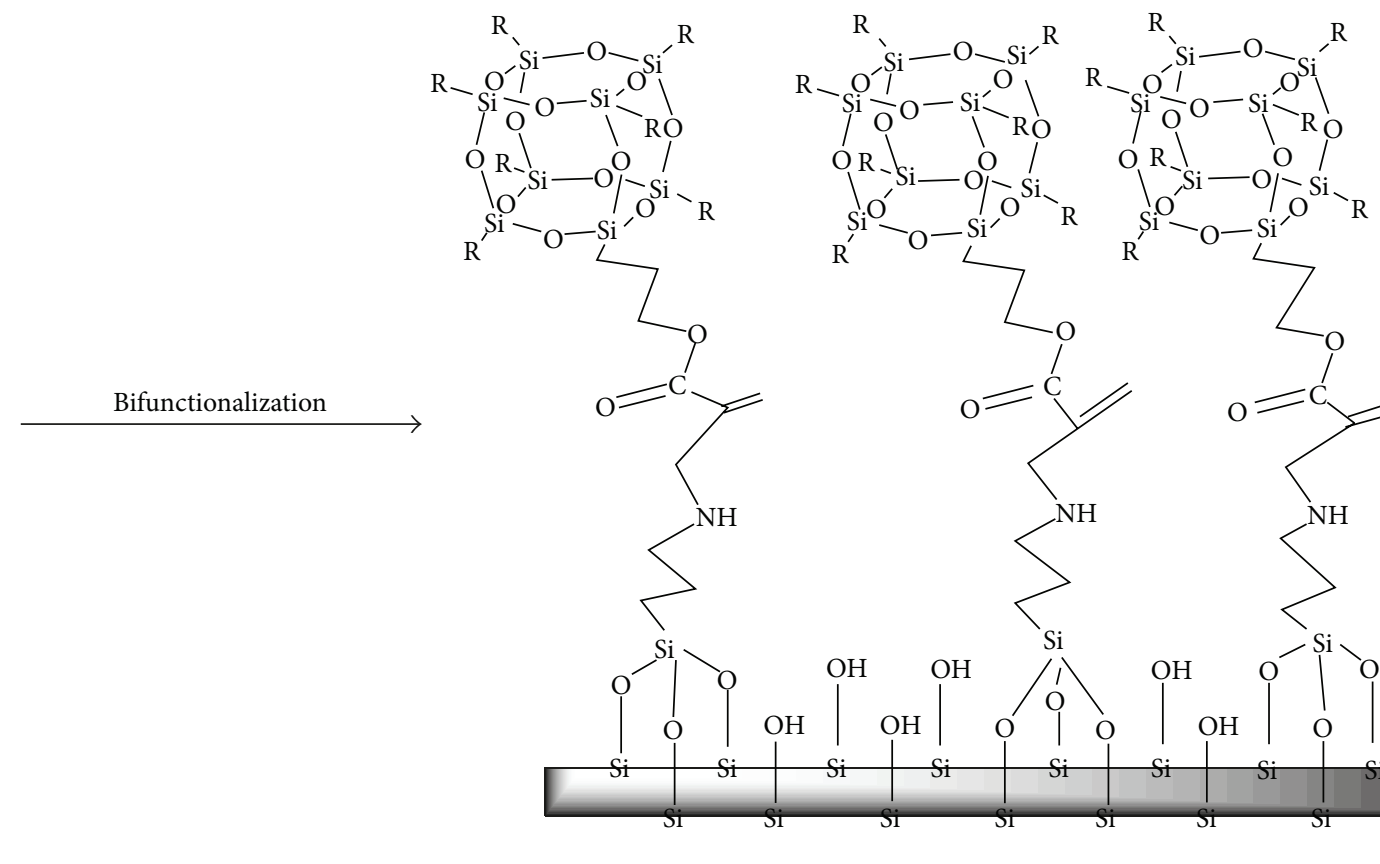

$\mathrm{SiO}_{2} /$ silane/POSS hybrid filler

(b)

FIGURe 2: Continued. 


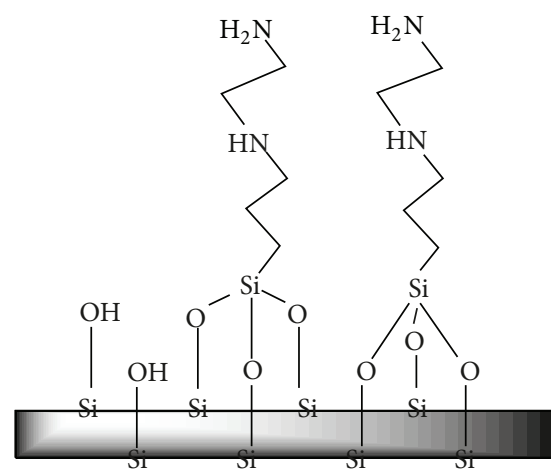

Silane modified silica surface<smiles>[R][R]1([R])O[Si]2([R])O[Si]3([R])O[Si]([R])(O1)O[Si]1([R])O[Si]([R])(O2)O[Si]([R])(O3)O1</smiles>

POSS compound $8 \mathrm{R}=\mathrm{CH}_{2}=\mathrm{C}\left(\mathrm{CH}_{2}\right) \mathrm{COOC}_{3} \mathrm{H}_{7}$ $n=8,10,12(n=8$ shown $)$
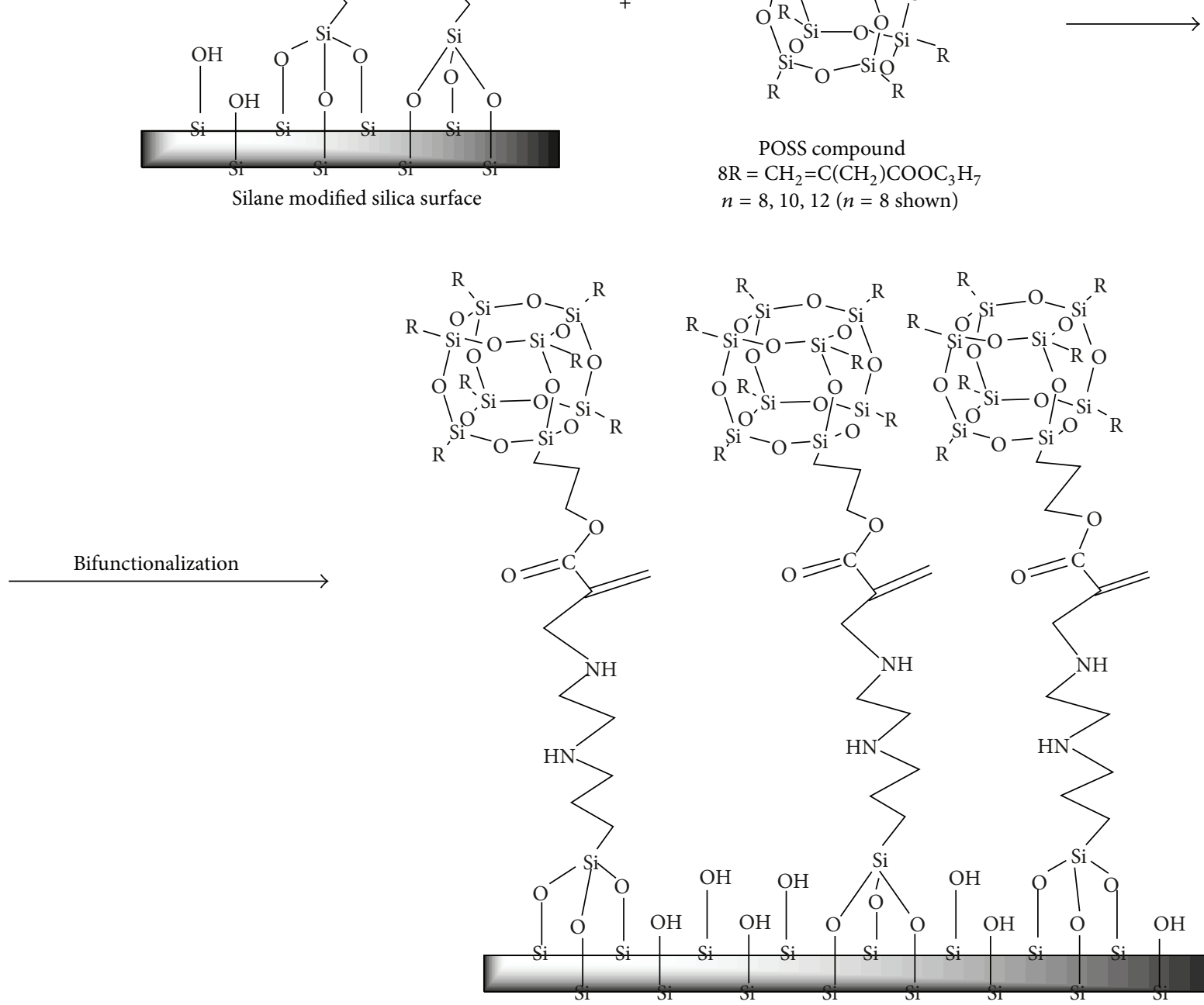

(c)

FIGURE 2: Predicted mechanism of silica surface bifunctionalization: silica surface silanization (a), bifunctionalization (3isocyanatopropyl)triethoxysilane and Methacryl POSS Cage Mixture (b), and N-2-(aminoethyl)-3-aminopropyltrimethoxysilane and Methacryl POSS Compound (c).

The degree of silica surface coverage increases from $0.38 \mu \mathrm{mol} / \mathrm{m}^{2}$ for the silica modified with 5 weight parts by mass of isocyanate silane and 3 weight parts by mass of POSS compound to $0.53 \mu \mathrm{mol} / \mathrm{m}^{2}$ for the silica modified with the same amount of the silane and 10 weight parts by mass of Methacryl POSS Cage Mixture (samples 5C, 6C, and 7C). Analogous situation was observed for samples $4 \mathrm{D}, 5 \mathrm{D}$, and $6 \mathrm{D}$, modified with 5 weight parts by mass of aminosilane and POSS compound in different amounts. The degree of coverage for those samples increases from the value of $0.35 \mu \mathrm{mol} / \mathrm{m}^{2}$ (the lowest amount of POSS compound used) to $0.69 \mu \mathrm{mol} / \mathrm{m}^{2}$, after aminosilane-grafted silica functionalization with 10 weight parts by mass of Methacryl POSS Cage Mixture.

3.3. Characteristics of Porous Structure of Unmodified Silica and $\mathrm{SiO}_{2} /$ Silane/POSS Systems. At the next stage of the study, parameters of porous structure of modified $\mathrm{SiO}_{2}$ samples were characterized. The fundamental parameters determining the surface activity of the modified samples are specific surface area $\left(S_{\mathrm{BET}}\right)$ and pore size distribution, evaluated according to nitrogen adsorption/desorption isotherms presented in Figure 7. 


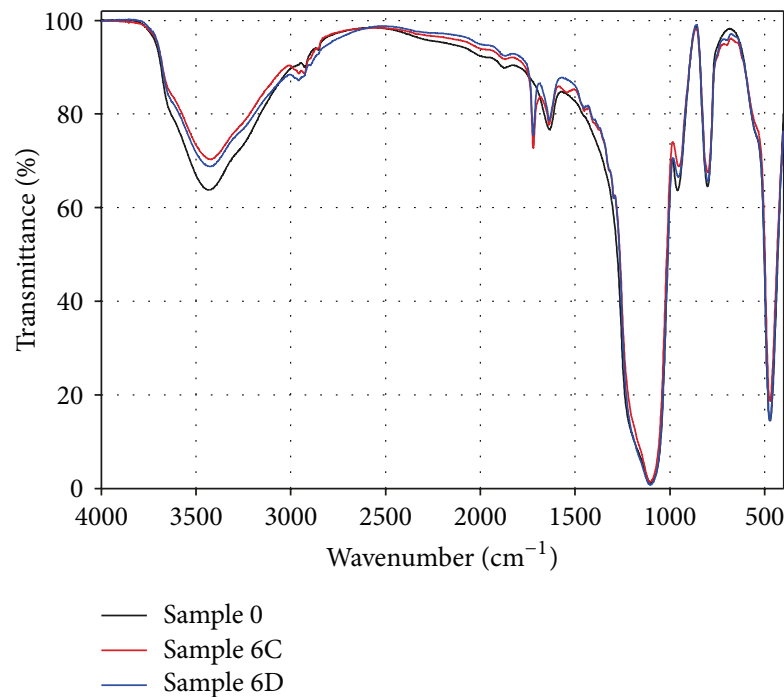

(a)

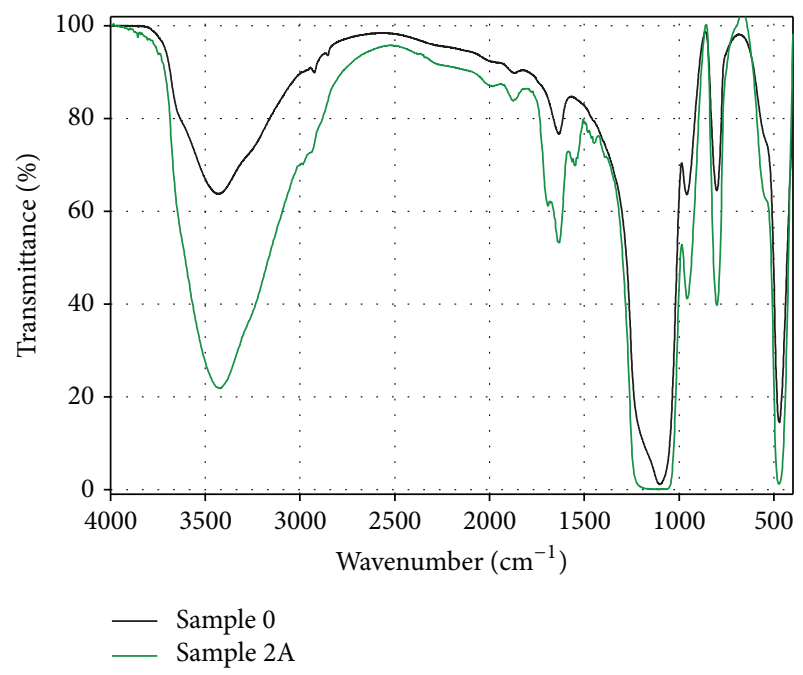

(c)

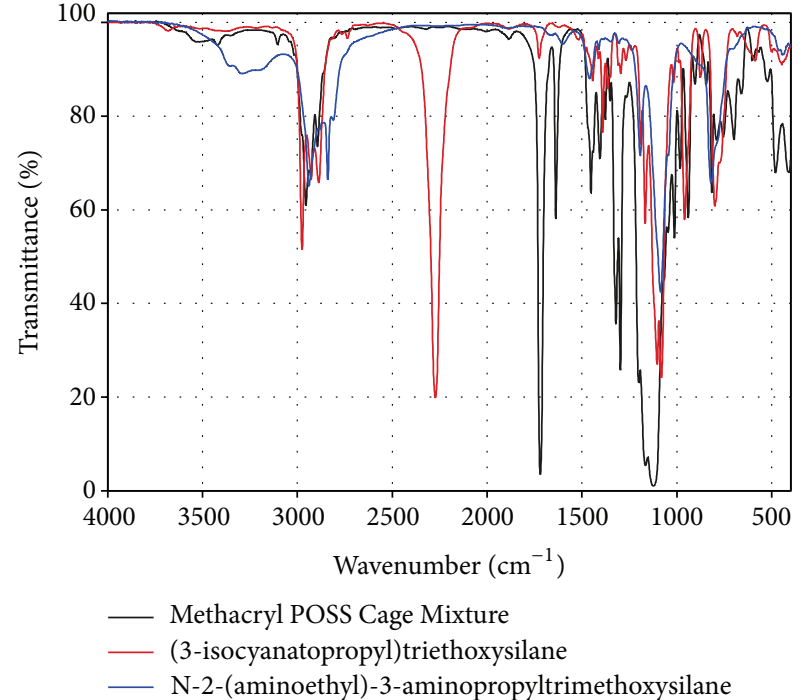

(b)

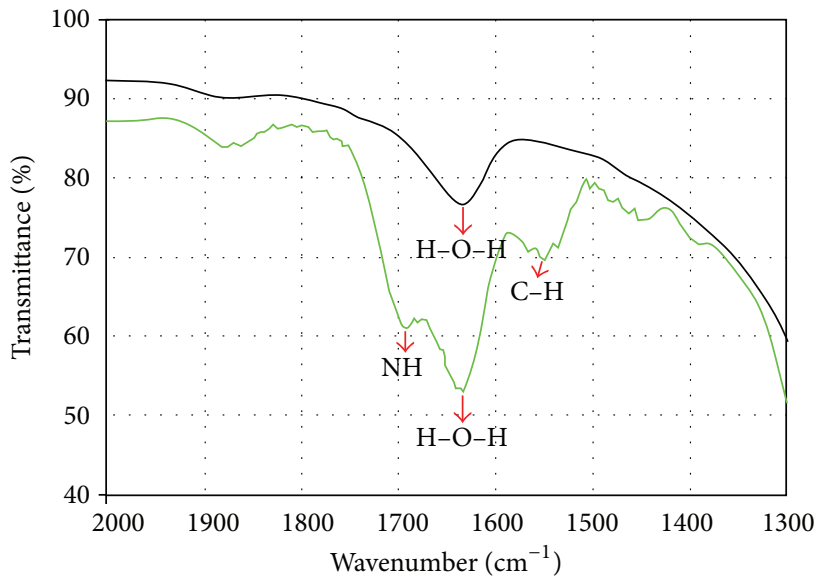

(d)

FIgUre 3: The FTIR spectra of $\mathrm{SiO}_{2}$ functionalized with selected silanes and different amounts of Methacryl POSS Cage Mixture (a), pure alkoxysilanes and Methacryl POSS Cage Mixture (b), and $\mathrm{SiO}_{2}$ functionalized with 5 weight parts by mass of (3isocyanatopropyl)triethoxysilane ((c), (d)).

Analysis of the data presented in Figure 7 shows that the greater the amount of the modifying agent is, the smaller the surface area $\left(S_{\mathrm{BET}}\right)$ is. Most probably, it is a consequence of blocking of the active centres (surface silanol groups) on the silica by the molecules of modifier. The isotherms estimated for $\mathrm{SiO}_{2}$-based fillers were classified as type IV and $\mathrm{H} 3$ type hysteresis loop, indicating the mesoporous character of the samples. The isotherms of samples obtained cover the relative pressure range $p / p_{0}=0.6-1.0$. A considerable decrease in the surface area (Table 4), relative to that of the unmodified sample, was observed for the sample 6C-modified with 5 weight parts by mass of (3-isocyanatopropyl)triethoxysilane and 10 weight parts by mass of POSS mixture as well as for the sample $6 \mathrm{D}-$ functionalized with 5 weight parts by mass of N-2-(aminoethyl)-3-aminopropyltrimethoxysilane and 10 weight parts by mass of Methacryl POSS Cage Mixture (Table 5). The surface area of sample $6 \mathrm{C}$ was $11 \mathrm{~m}^{2} / \mathrm{g}$. The effect of $\mathrm{SiO}_{2}$ modification with N-2-(aminoethyl)-3aminopropyltrimethoxysilane was smaller as the specific surface area of the samples modified with 5 weight parts by mass of this silane and 3 and 5 or 10 weight parts by mass of POSS compound was 31,22 , and $17 \mathrm{~m}^{2} / \mathrm{g}$, respectively. The nitrogen volume adsorbed on unmodified silica matrix reaches $250 \mathrm{~cm}^{3} / \mathrm{g}$ at $p / p_{0}=1.0$. For bifunctionalized $\mathrm{SiO}_{2}$ samples (Figure 7), the nitrogen volume adsorbed at $p / p_{0}=$ 1.0 was much lower $\left(125 \mathrm{~cm}^{3} / \mathrm{g}\right.$ for sample $6 \mathrm{C}$ and $90 \mathrm{~cm}^{3} / \mathrm{g}$ for sample 6D). Addition of any of the modifiers also resulted in a decrease in the pore diameters as well as in their volume. The changes were more significant when a higher amount of a modifying compound was used. In the case of systems 


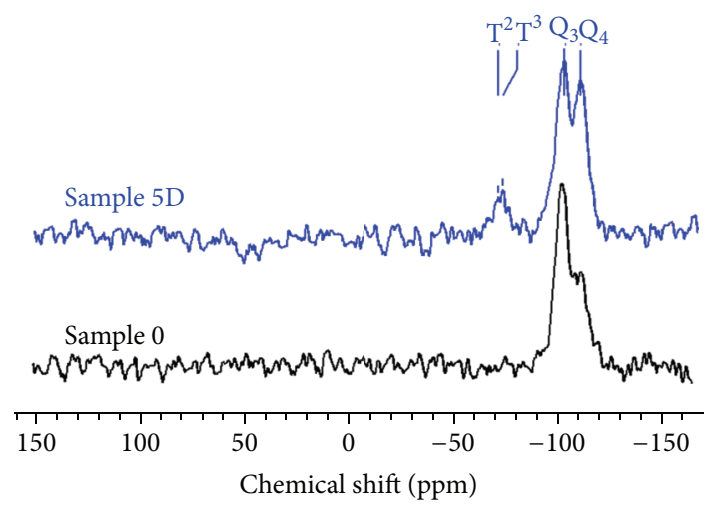

FIgURE 4: The ${ }^{29} \mathrm{Si}$ CP MAS NMR spectra of unmodified silica (sample 0) and $\mathrm{SiO}_{2}$ functionalized with aminosilane and Methacryl POSS Cage Mixture (sample 5D).

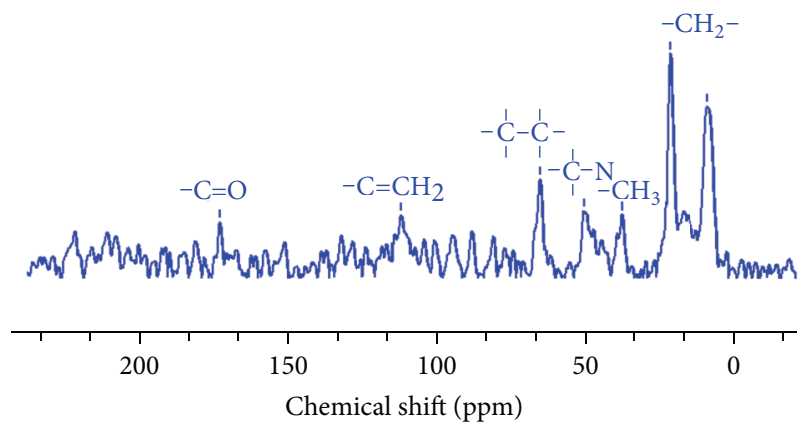

Figure 5: The ${ }^{13} \mathrm{C}$ CP MAS NMR spectrum of $\mathrm{SiO}_{2}$ functionalized with aminosilane and Methacryl POSS Cage Mixture (Sample 5D).

TABLE 3: Elemental content of carbon, nitrogen, and hydrogen in silica-based fillers grafted with alkoxysilanes and different amounts of Methacryl POSS Cage Mixture.

\begin{tabular}{lccc}
\hline Sample no. & \multicolumn{3}{c}{ Elemental content (\%) } \\
\hline 0 & $\mathrm{C}$ & $\mathrm{N}$ & $\mathrm{H}$ \\
\hline $4 \mathrm{C}$ & 0.139 & - & 1.027 \\
$5 \mathrm{C}$ & 2.346 & 0.235 & 1.624 \\
$6 \mathrm{C}$ & 3.537 & 0.247 & 1.664 \\
$4 \mathrm{D}$ & 5.253 & 0.251 & 1.703 \\
$5 \mathrm{D}$ & 2.242 & 0.524 & 1.687 \\
$6 \mathrm{D}$ & 3.414 & 0.534 & 1.751 \\
\hline
\end{tabular}

obtained with the use of isocyanate silane, pore volume decreases after silica functionalization from $0.37 \mathrm{~cm}^{3} / \mathrm{g}$ to $0.01 \mathrm{~cm}^{3} / \mathrm{g}$. On the other hand, pore diameter increase after silica surface bifunctionalization was observed.

3.4. Dispersive and Morphological Properties of the Fillers Obtained. In the next stage of the research, the particle sizes of grafted and bifunctionalized hybrid fillers were estimated. The experimental data collected were used to determine the influence of the quantity of modifying agents on the degree of agglomeration of the particles. SEM and TEM images

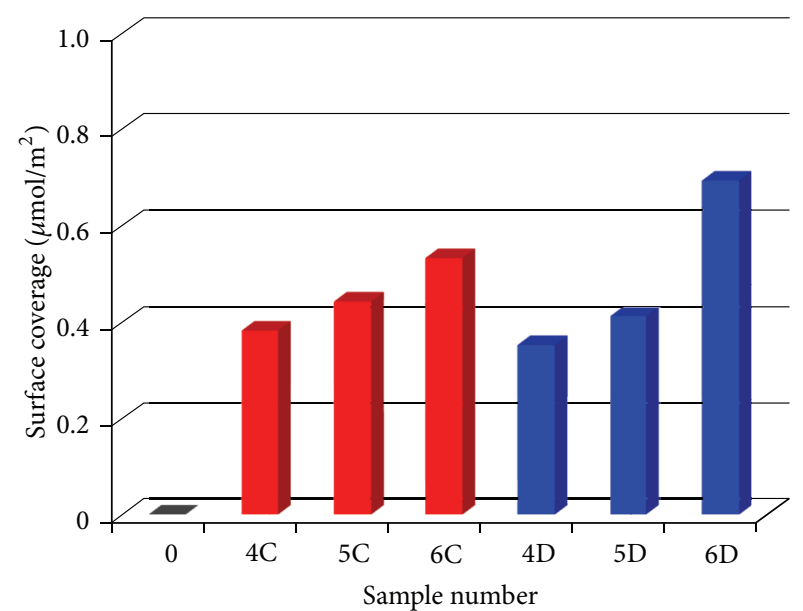

FIGURE 6: The degree of silica surface coverage with selected alkoxysilanes and different amounts of Methacryl POSS Cage Mixture.

TABLE 4: Characteristics of porous structure of hydrated silica and hybrid fillers obtained using different amounts of silanes and Methacryl POSS Cage Mixture.

\begin{tabular}{lccc}
\hline Sample no. & $S_{\text {BET }}\left(\mathrm{m}^{2} / \mathrm{g}\right)$ & $V_{p}\left(\mathrm{~cm}^{3} / \mathrm{g}\right)$ & $D_{p}(\mathrm{~nm})$ \\
\hline 0 & 110 & 0.37 & 13 \\
4C & 23 & 0.11 & 27 \\
5C & 22 & 0.01 & 23 \\
6C & 11 & 0.01 & 21 \\
4D & 31 & 0.12 & 27 \\
5D & 22 & 0.01 & 27 \\
6D & 17 & 0.01 & 23 \\
\hline
\end{tabular}

of the initial hydrated silica and selected systems functionalized with alkoxysilanes are presented in Table 5. The application of 5 weight parts by mass of organosilane was found to be the most suitable. Larger quantities of alkoxysilanes cause primary particles to combine into large agglomerates. SEM images show that fillers obtained using $\mathrm{N}$-2-(aminoethyl)-3-aminopropyltrimethoxysilane display a higher tendency towards agglomeration than (3-isocyanatopropyl)triethoxysilane. In the case of sample 2A, (modified with 5 weight parts by mass of isocyanate silane) $10 \%$ of particles $[d(0.1)]$ have diameters not greater than $3.81 \mu \mathrm{m}, 50 \%$ of particles $[d(0.5)]$ have diameters not greater than $13.71 \mu \mathrm{m}$, and $90 \%[d(0.9)]$ have diameters not greater than $38.82 \mu \mathrm{m}$. The mean diameter of particles in this sample [D[4.3]] is equal to $18.04 \mu \mathrm{m}$. The particle size parameters of a filler modified with 5 weight parts by mass of aminosilane (sample 2B) are higher. Moreover, it was noted that the value of the parameter $[d(0.9)]$ is $46.10 \mu \mathrm{m}$, which means that $90 \%$ of the sample volume is occupied by particles with smaller diameters, and the mean diameter of particles in this sample $[D[4.3]]$ is equal to $21.93 \mu \mathrm{m}$.

The dispersive characteristics of hybrids functionalized with alkoxysilanes and Methacryl POSS Cage Mixture were also determined. Table 6 presents the 


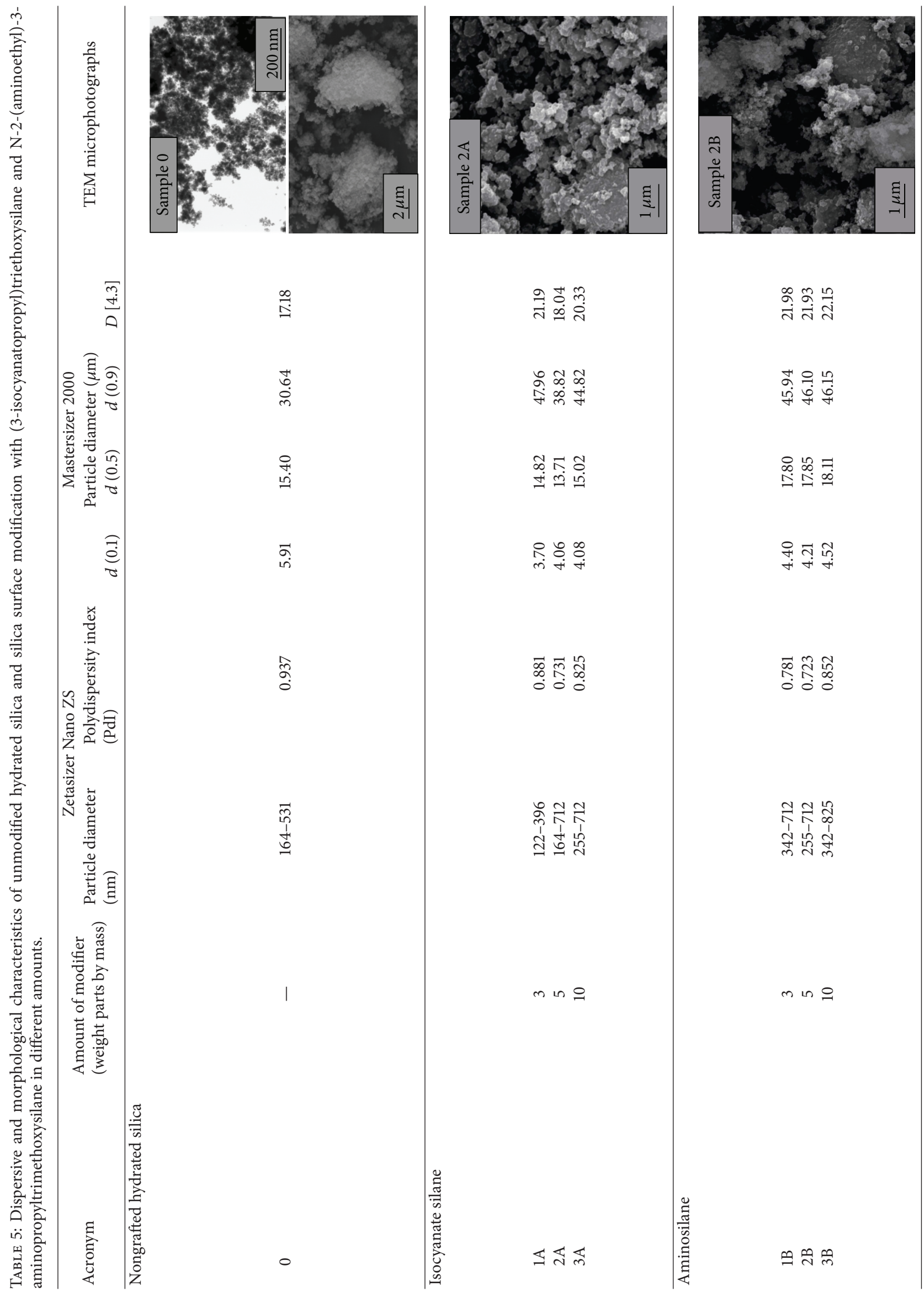




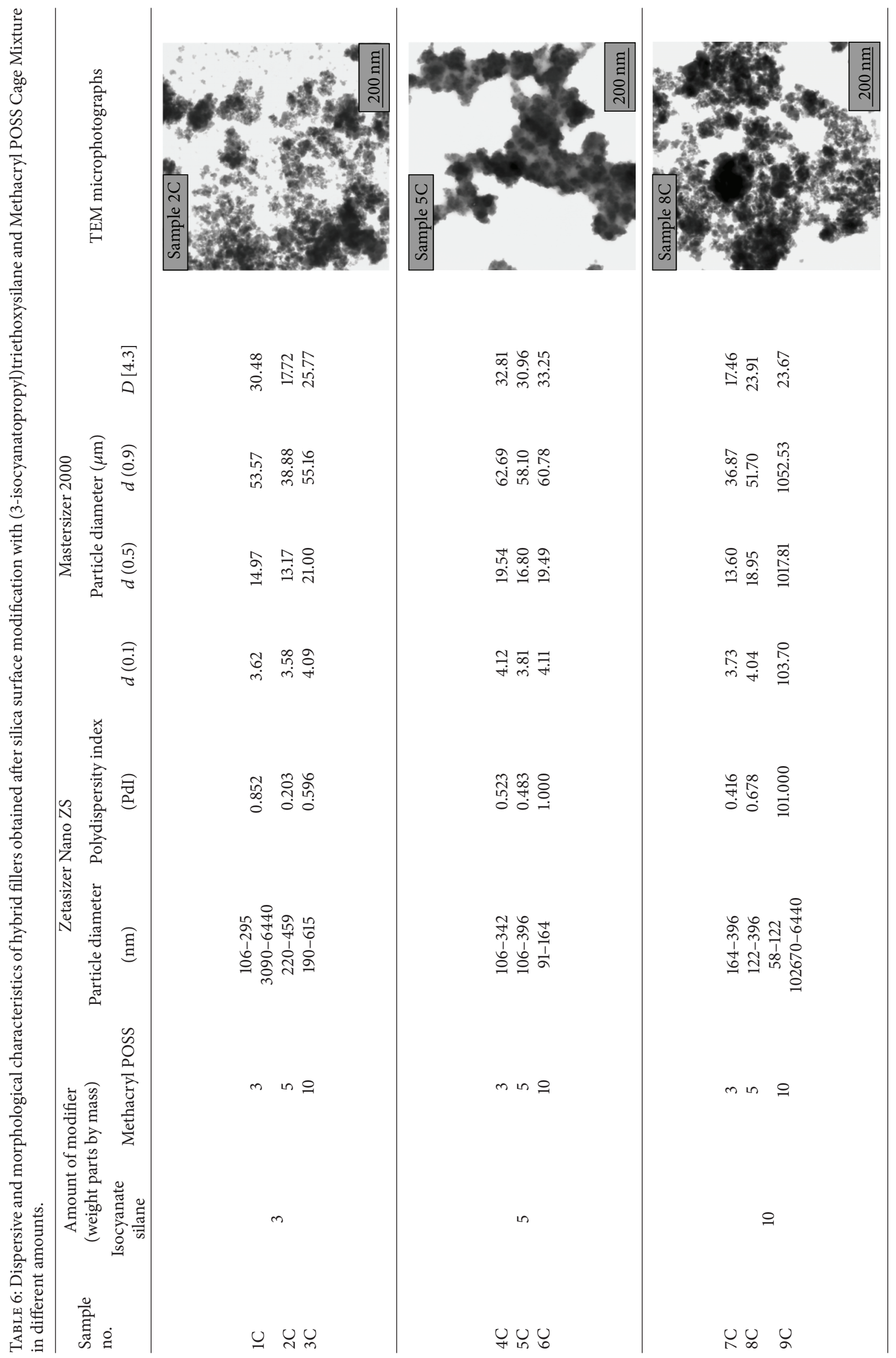




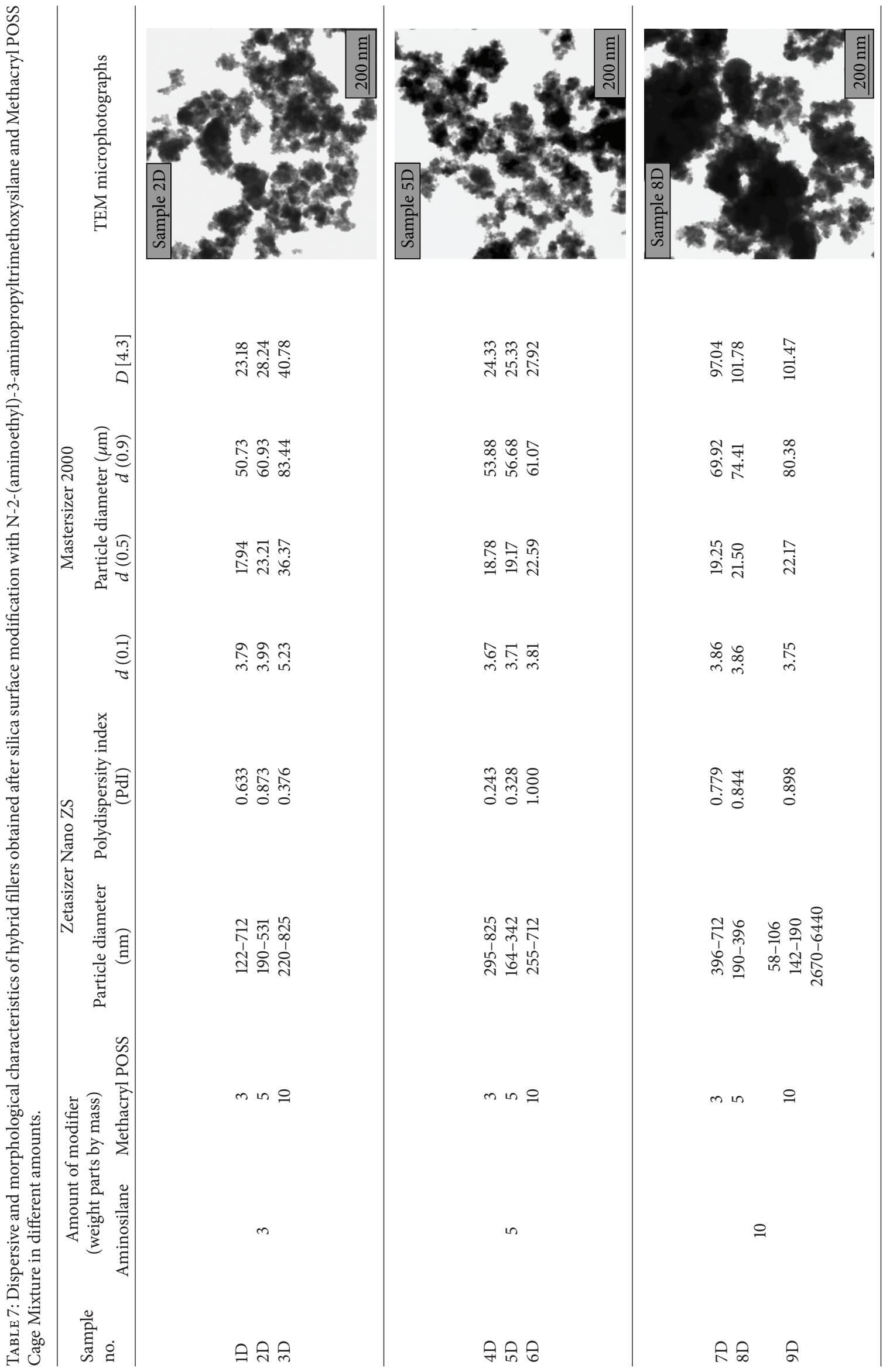




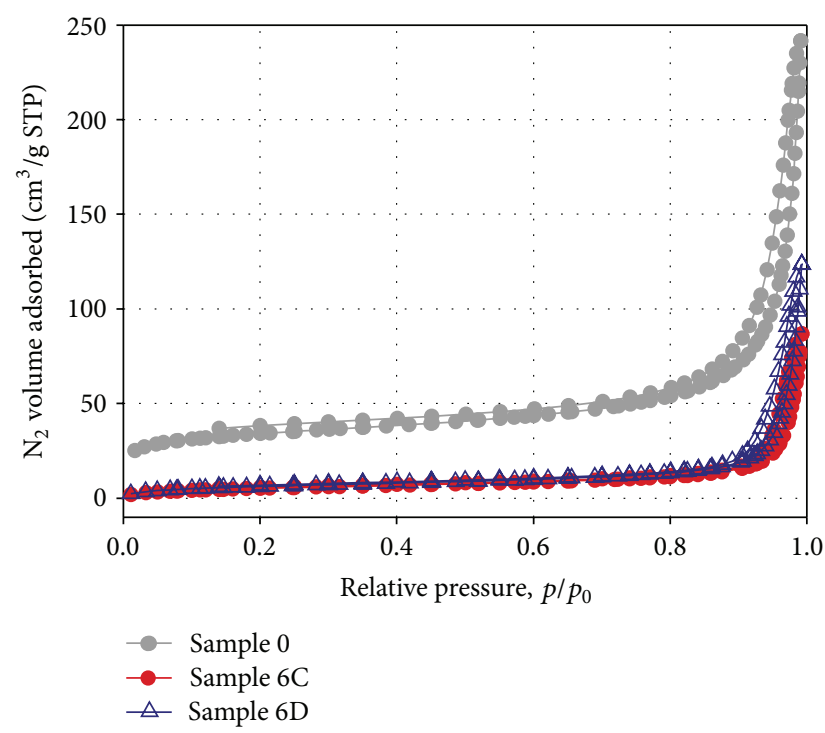

(a)

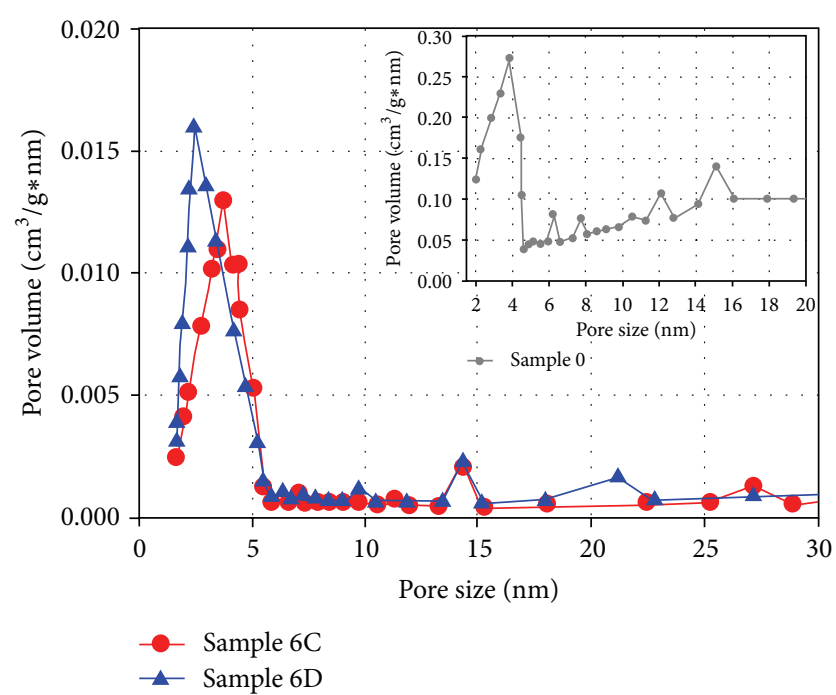

(b)

FIGURE 7: Nitrogen adsorption/desorption isotherms (a) and pore size distribution (b) for unmodified hydrated silica and hybrid fillers obtained using 5 weight parts by mass of (3-isocyanatopropyl)triethoxysilane and 10 weight parts by mass of POSS mixture (Sample 6C) and 5 weight parts by mass of N-2-(aminoethyl)-3-aminopropyltrimethoxysilane and 10 weight parts by mass of Methacryl POSS (Sample 6D).

dispersive/morphological characteristics of unmodified silica support and hybrid systems obtained after $\mathrm{SiO}_{2}$ modification with (3-isocyanatopropyl)triethoxysilane and oligomeric silsesquioxane with methacrylate substituents. Significant changes in the dispersive character of fillers obtained were noted. Results of the analysis revealed that in sample 5C, obtained after silica support functionalization with 5 weight parts by mass of (3-isocyanatopropyl)triethoxysilane and Methacryl POSS Cage Mixture, $10 \%$ of particles $[d(0.1)]$ have diameters not greater than $4.06 \mu \mathrm{m}, 50 \%$ of particles $[d(0.5)]$ have diameters not greater than $16.80 \mu \mathrm{m}$, and $90 \%[d(0.9)]$ have diameters not greater than $58.10 \mu \mathrm{m}$. The mean diameter of particles in this sample $[D[4.3]]$ equals to $30.96 \mu \mathrm{m}$. A significant increase in the size of particles of hybrid systems obtained, compared to the initial silica support particle diameters (sample 0), was observed. Those results also indicate that bifunctionalized fillers particles show higher tendency towards agglomeration (Table 6). This is probably due to the hydrophilic nature of $\mathrm{SiO}_{2}$ support. TEM images of selected fillers inform about the presence of primary particles as well as larger clusters, evidence of the presence of secondary agglomerates, which confirms the results obtained testing the dispersive properties.

A similar tendency towards agglomeration was observed for hybrid systems obtained using different amounts of $\mathrm{N}$ 2-(aminoethyl)-3-aminopropyltrimethoxysilane and Methacryl POSS Cage Mixture. Results are presented in Table 7. Bifunctionalization process, sequentially with aminosilane and methacrylate-substituted POSS compound, have contributed significantly to fillers particle agglomera tion. In the sample obtained using 10 weight parts by mass of aminosilane and 5 weight parts by mass of Methacryl POSS (sample 8D), $10 \%$ of particles have diameters not greater than $3.86 \mu \mathrm{m}$,

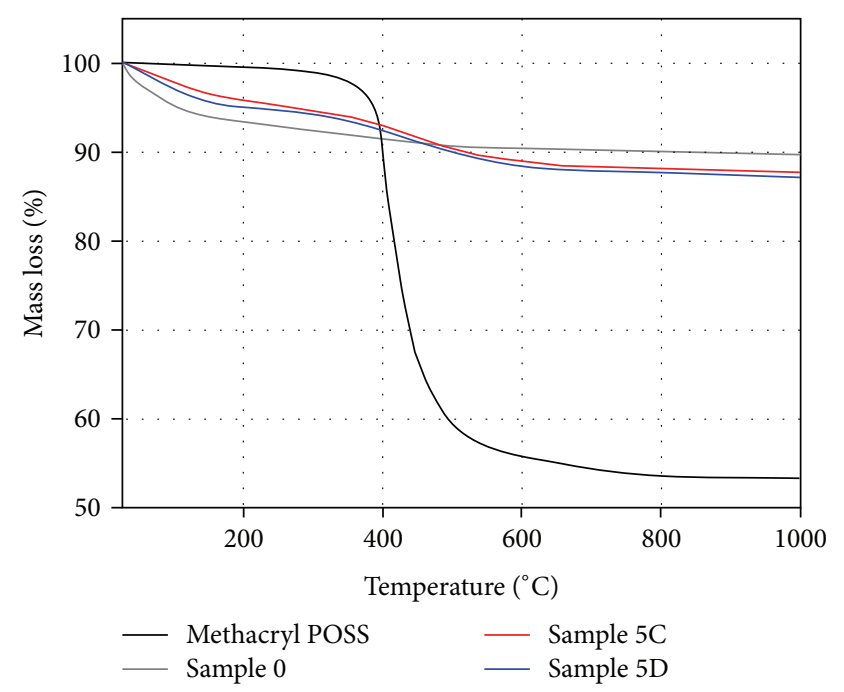

FIGURE 8: Thermograms of pure Methacryl POSS Cage Mixture and hybrid system obtained after modification of $\mathrm{SiO}_{2}$ with 5 weight parts by mass of isocyanate silane or aminosilane and 5 weight parts by mass of Methacryl POSS Cage Mixture.

$50 \%$ of particles have diameters not greater than $21.50 \mu \mathrm{m}$, and $90 \%$ have diameters not greater than $74.41 \mu \mathrm{m}$. For all samples, a significant increase in particle diameters compared to the initial silica support was noted, as reflected in the attached TEM images of the selected fillers.

3.5. Thermogravimetric Analysis. Figure 8 shows TGA thermograms of pure silsesquioxane with methacrylate groups, unmodified hydrated silica, and the hybrid fillers obtained 


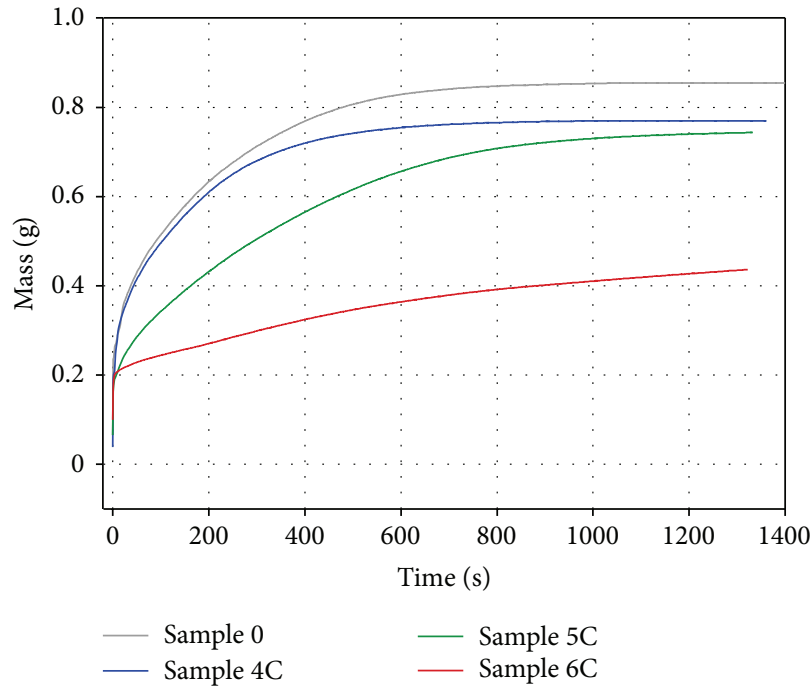

(a)

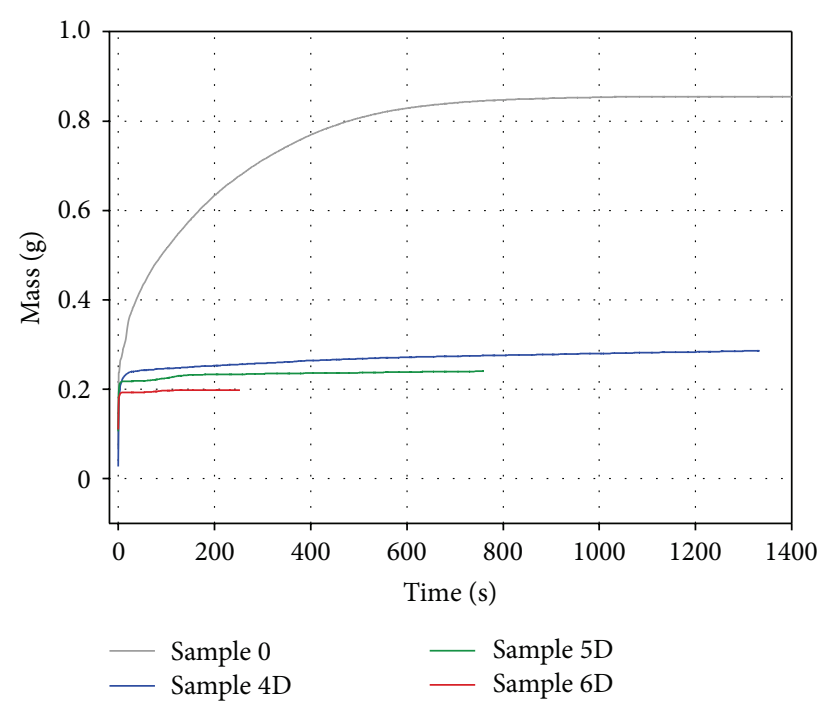

(b)

FIGURE 9: The wettability profiles of $\mathrm{SiO}_{2}$ functionalized with (3-isocyanatopropyl)triethoxysilane (a), N-2-(aminoethyl)-3-aminopropyltrimethoxysilane (b), and different amounts of Methacryl POSS Cage Mixture.

after silica surface functionalization with 5 weight parts by mass of aminosilane, isocyanate silane, and 5 weight parts by mass of Methacryl POSS Cage Mixture.

For hydrated silica (sample 0), the process of decomposition begins at a temperature of $30^{\circ} \mathrm{C}$, and it can be stated to be a one-stage process. The observed mass loss in the temperature range $30-125^{\circ} \mathrm{C}$ is relatively rapid, as it is indicated by the intense fall in mass recorded on the thermogravimetric curve. After the temperature exceeds $\sim 700^{\circ} \mathrm{C}$, the sample stabilizes, and its mass remains almost unchanged. The analysis showed that within the aforementioned temperature range, pure hydrated silica loses only $10 \%$ of its total mass. Thermogravimetric analysis of hybrid systems was performed to evaluate their thermal stability. Sequentially obtained thermograms were compared with the diagram obtained for the pure POSS modifier. For selected hybrid systems (samples 5C and 5D), a two-step degradation process was noted. The first mass loss observed in the range from 30 to about $300^{\circ} \mathrm{C}$ is most likely related to dehydration (loss of chemically and physically bonded water). In this temperature range, the filler mass loss is just over 7\%. Subsequent TGA curve inflection occurs at a temperature $\sim 325^{\circ} \mathrm{C}$. This mass loss is probably related with the decomposition of functional groups of modifying agent. Mass of tested fillers stabilizes at $700^{\circ} \mathrm{C}$, and the total loss of weight in the temperature range $30-1000^{\circ} \mathrm{C}$ is $13 \%$. It was observed that the change of modifier virtually has no effect on changes in the thermogravimetric curves, and thus on the thermal stability of different hybrid fillers. The TGA curve of pure POSS revealed a mass loss of about $43 \%$ at $550^{\circ} \mathrm{C}$. The process continued until total degradation of the organic groups substituted at the silicon atoms of the POSS skeleton. Application of silica filler as a support for hybrid systems preparation caused a significant decrease in the total mass loss and thermal stability shift, which is very important in terms of using such systems in the polymer processing and other useful materials.

3.6. Evaluation of Hydrophilic/Hydrophobic Surface Character of Hybrid Systems Obtained. The wettability with water of the initial silica and the hybrid systems was tested to evaluate the hydrophobic or hydrophilic character of the products obtained. According to the data shown in Figure 9(a), the mass increase in time is smaller for the modified silica, so it has lower affinity to water than the unmodified one. Thus, modification process (using (3isocyanatopropyl)triethoxysilane and Methacryl POSS Cage Mixture in different amounts) has resulted in hydrophobization of the silica surface. Figure 9(b) presents the mass increase in time for the fillers obtained after silica modification with $\mathrm{N}$-2-(aminoethyl)-3-aminopropyltrimethoxysilane and different amounts of Methacryl POSS Cage Mixture. The mass increase is smaller once again for the modified silica, which proves its hydrophobic character.

\section{Conclusions}

The proposed methacrylate substituents support surface bifunctionalization should be classified as an innovative chemical method. The research obtained through the evaluation of the elemental composition and FTIR as well as ${ }^{13} \mathrm{C}$ and ${ }^{29} \mathrm{Si}$ CP MAS NMR spectroscopies also confirmed the effectiveness of the bifunctionalization process.

It was also confirmed that an incorporation of the silane coupling agents and Methacryl POSS on the support surface contributed to an increase in the hydrophobic nature of the filler obtained together with a decrease of the values of their surface area, as compared to the unmodified silica. 
Changes in the thermal stability of $\mathrm{SiO}_{2}$ /silane/POSS hybrids, in comparison to pure POSS modifier, were also noted. Moreover, the functionalization of hydrated silica surface, using selected modifying substances, caused a change in the dispersive character of hybrid systems produced.

Those innovative hybrid fillers, with a high hydrophobicity, are successfully used in the filling of a polymer matrixes. In addition, easy control of the production process of such fillers and a possibility of silsesquioxane cage corners substitution with a wide variety of reactive organic groups, cause their great dispersion in elastomers, high adhesion, and chemisorption to a polymer.

\section{Conflict of Interests}

The authors declared no conflict of interests in respect of our submitted paper.

\section{Authors' Contribution}

The authors informed equal contribution of each author in this paper.

\section{Acknowledgment}

The study was realized within the Poznan University of Technology research Grant no. 32-375/2013-DS.

\section{References}

[1] P. D. Lickiss and F. Rataboul, "Fully condensed Polyhedral Oligosilsesquioxanes (POSS): from synthesis to application," Advances in Organometallic Chemistry, vol. 57, pp. 1-116, 2008.

[2] Q. Tai, R. K. K. Yuen, L. Song, and Y. Hu, "A novel polymeric flame retardant and exfoliated clay nanocomposites: preparation and properties," Chemical Engineering Journal, vol. 183, pp. 542-549, 2012.

[3] J. Wu and P. T. Mather, "POSS Polymers: physical properties and biomaterials applications," Journal of Macromolecular Science Part C, vol. 49, no. 1, pp. 25-63, 2009.

[4] H. Xu, S.-W. Kuo, J.-S. Lee, and F.-C. Chang, "Preparations, thermal properties, and $\mathrm{Tg}$ increase mechanism of inorganic/organic hybrid polymers based on Polyhedral Oligomeric Silsesquioxanes," Macromolecules, vol. 35, no. 23, pp. 8788-8793, 2002.

[5] H. Xu, B. Yang, J. Wang, S. Guang, and C. Li, "Preparation, thermal properties, and Tg increase mechanism of poly(acetoxystyrene-co-octavinyl-polyhedral oligomeric silsesquioxane) hybrid nanocomposites," Macromolecules, vol. 38, no. 25, pp. 10455-10460, 2005.

[6] A. Lee and J. D. Lichtenhan, "Viscoelastic responses of polyhedral oligosilsesquioxane reinforced epoxy systems," Macromolecules, vol. 31, no. 15, pp. 4970-4974, 1998.

[7] A. Fina, D. Tabuani, T. Peijs, and G. Camino, "POSS grafting on PPgMA by one-step reactive blending," Polymer, vol. 50, no. 1, pp. 218-226, 2009.

[8] G. Z. Li, H. Cho, L. Wang, H. Toghiani, and C. U. Pittman Jr., "Synthesis and properties of poly(isobutyl methacrylateco-butanediol dimethacrylate-co-methacryl polyhedral oligomeric silsesquioxane) nanocomposites," Journal of Polymer Science Part A, vol. 43, no. 2, pp. 355-372, 2005.

[9] F. Mammeri, C. Bonhomme, F. Ribot, F. Babonneau, and S. Diré, "New monofunctional POSS and its utilization as dewetting additive in methacrylate based free-standing films," Chemistry of Materials, vol. 21, no. 2, pp. 4163-4171, 2009.

[10] E. Sarantopoulou, Z. Kollia, A. C. Cefalas, A. E. Siokou, P. Argitis, and V. Bellas, "Surface modification of polyhedral oligomeric silsesquioxane block copolymer films by $157 \mathrm{~nm}$ laser light," Journal of Applied Physics, vol. 105, Article ID 114305, pp. 114-305, 2009.

[11] Y. Qin, Y. Bi, H. Ren, F. Zhu, M. Luo, and L. Zhang, "Poly(methyl methacrylate)/methacryl-POSS nanocomposites with excellent thermal properties," Chinese Journal of Chemistry, vol. 28, no. 12, pp. 2527-2532, 2010.

[12] O. H. Lin, Z. A. Mohd Ishak, and H. M. Akil, "Preparation and properties of nanosilica-filled polypropylene composites with PP-methyl POSS as compatibiliser," Materials and Design, vol. 30, no. 3, pp. 748-751, 2009.

[13] S.-W. Kuo and F.-C. Chang, "POSS related polymer nanocomposites," Progress in Polymer Science, vol. 36, pp. 1649-1696, 2011.

[14] H. Fong, S. H. Dickens, and G. M. Flaim, "Evaluation of dental restorative composites containing polyhedral oligomeric silsesquioxane methacrylate," Dental Materials, vol. 21, no. 6, pp. 520-529, 2005.

[15] P. A. Wheeler, B. X. Fu, J. D. Lichtenhan, W. Jia, and L. J. Mathias, "Incorporation of metallic POSS, POSS copolymers, and new functionalized POSS compounds into commercial dental resins," Journal of Applied Polymer Science, vol. 102, no. 3, pp. 2856-2862, 2006.

[16] J. D. Liechtenhan, Y. A. Otonari, and M. J. Carr, "Linear hybrid polymer building blocks: methacrylate-functionalized polyhedral oligomeric silsesquioxane monomers and polymers," Macromolecules, vol. 28, no. 24, pp. 8435-8437, 1995.

[17] J. Zurawska, A. Krysztafkiewicz, and T. Jesionowski, "Physicochemical properties, surface morphology and particle size distribution of precipitated silicas," Surface and Interface Analysis, vol. 35, no. 11, pp. 914-921, 2003.

[18] Y. Nakahara, T. Takeuchi, S. Yokoyama, and K. Kimura, "Quantitative ${ }^{1} \mathrm{H}$ NMR analysis of reacted silanol groups in silica nanoparticles chemically modified with monochlorosilanes," Surface and Interface Analysis, vol. 43, no. 4, pp. 809-815, 2011.

[19] Z. Luo, X. Cai, R. Y. Hong, L. S. Wang, and W. G. Feng, "Preparation of silica nanoparticles using silicon tetrachloride for reinforcement of PU," Chemical Engineering Journal, vol. 187, pp. 357-366, 2012.

[20] X. Liu, L. Lei, Y. Li, H. Zhu, Y. Cui, and H. Hu, "Preparation of carriers based on magnetic nanoparticles grafted polymer and immobilization for lipase," Biochemical Engineering Journal, vol. 56, no. 3, pp. 142-149, 2011.

[21] F. Carniato, C. Bisio, E. Boccaleri, M. Guidotti, E. Gavrilova, and L. Marchese, "Titanosilsesquioxane anchored on mesoporous silicas: a novel approach for the preparation of heterogeneous catalysts for selective oxidations," Chemistry, vol. 14, no. 27, pp. 8098-8101, 2008.

[22] M. Bhagiyalakshmi, R. Anuradha, S. D. Park, and H. T. Jang, "Octa(aminophenyl)silsesquioxane fabrication on chlorofunctionalized mesoporous SBA-15 for $\mathrm{CO}_{2}$ adsorption," Microporous and Mesoporous Materials, vol. 131, no. 1-3, pp. 265-273, 2010.

[23] K. Szwarc, K. Siwinska-Stefanska, B. Marciniec, and T. Jesionowski, "Synthesis and characterisation of $\mathrm{SiO}_{2} / \mathrm{POSS}$ 
hybrid systems obtained using the mechanical method," Physicochememical Problems of Mineral Processing, vol. 48, no. 1, pp. 181-192, 2012.

[24] T. Jesionowski, J. Zurawska, A. Krysztafkiewicz, M. Pokora, D. Waszak, and W. Tylus, "Physicochemical and morphological properties of hydrated silicas precipitated following alkoxysilane surface modification," Applied Surface Science, vol. 205, no. 1-4, pp. 212-224, 2002.

[25] R. Y. Hong, H. P. Fu, Y. J. Zhang et al., "Surface-modified silica nanoparticles for reinforcement of PMMA," Journal of Applied Polymer Science, vol. 105, no. 4, pp. 2176-2184, 2007.

[26] W. Whitnall, T. Asefa, and G. A. Ozin, "Hybrid periodic mesoporous organosilicas," Advanced Functional Materials, vol. 15, no. 10, pp. 1696-1702, 2005.

[27] G. E. Berendsen and L. De Golan, "Preparation and chromatographic properties of some chemically bonded phases for reversed-phase liquid chromatotography," Journal of Liquid Chromatography, vol. 1, no. 5, pp. 561-586, 1978. 

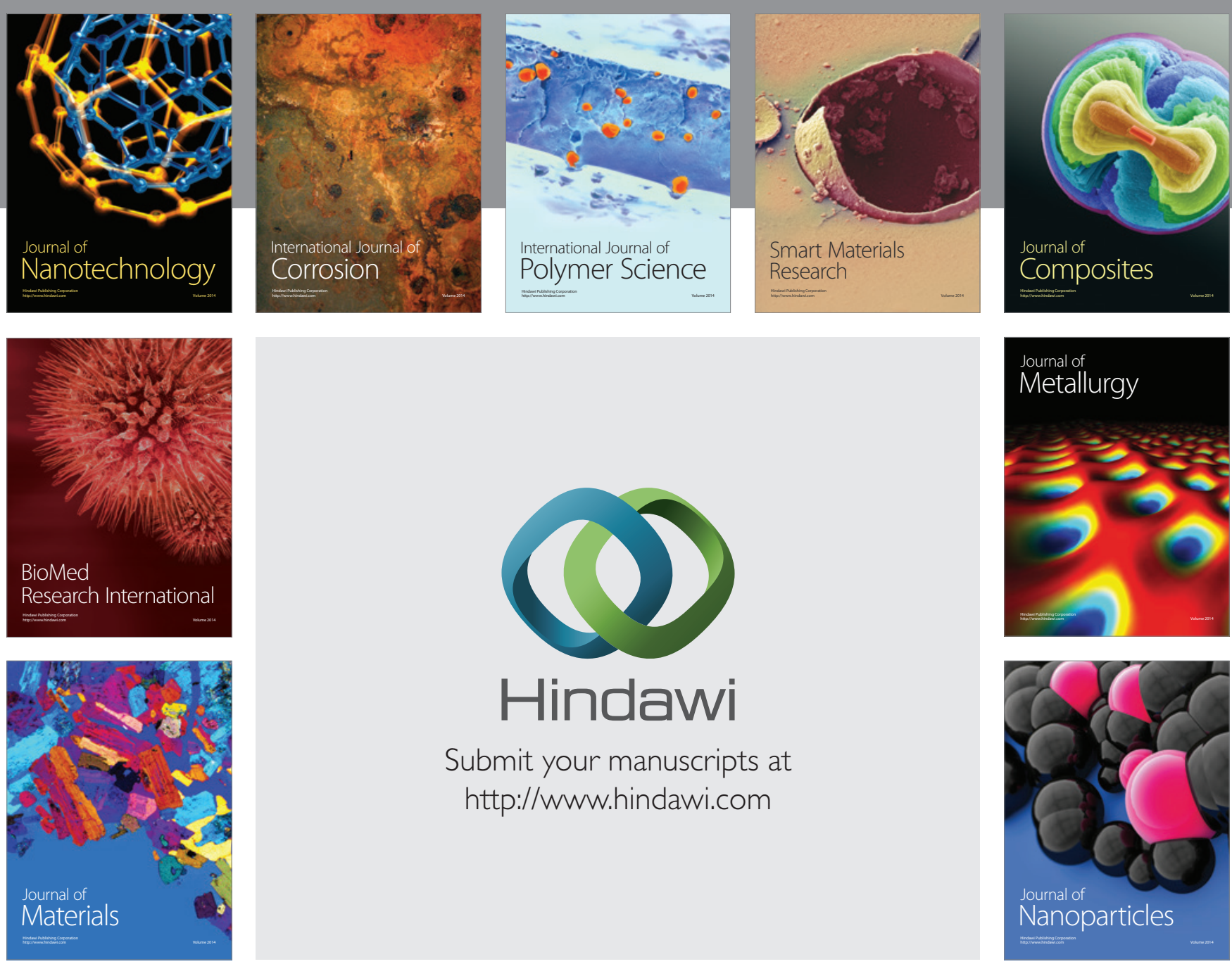

Submit your manuscripts at http://www.hindawi.com
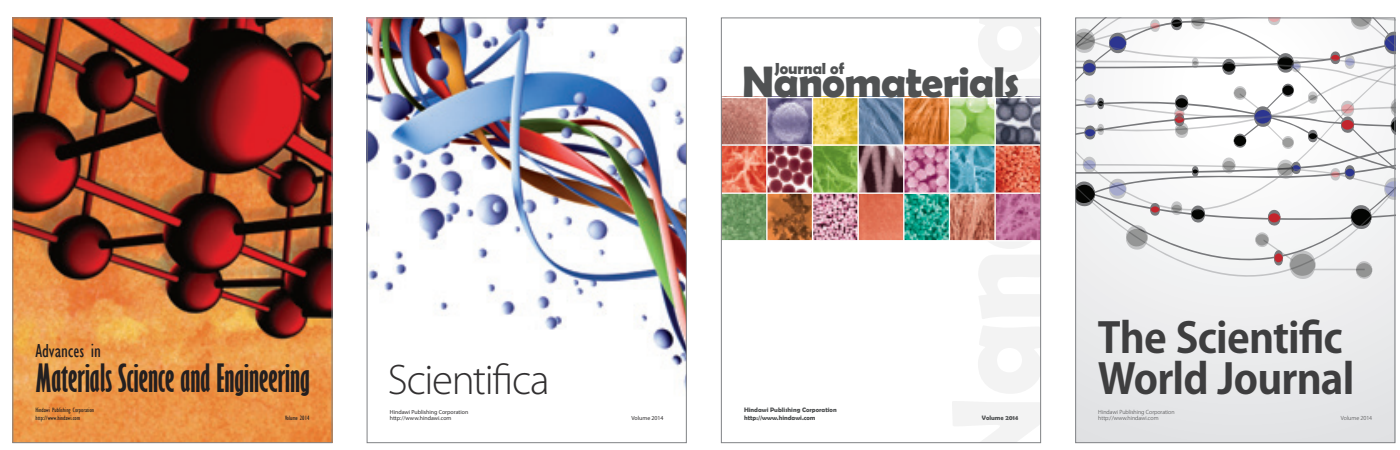

\section{The Scientific World Journal}
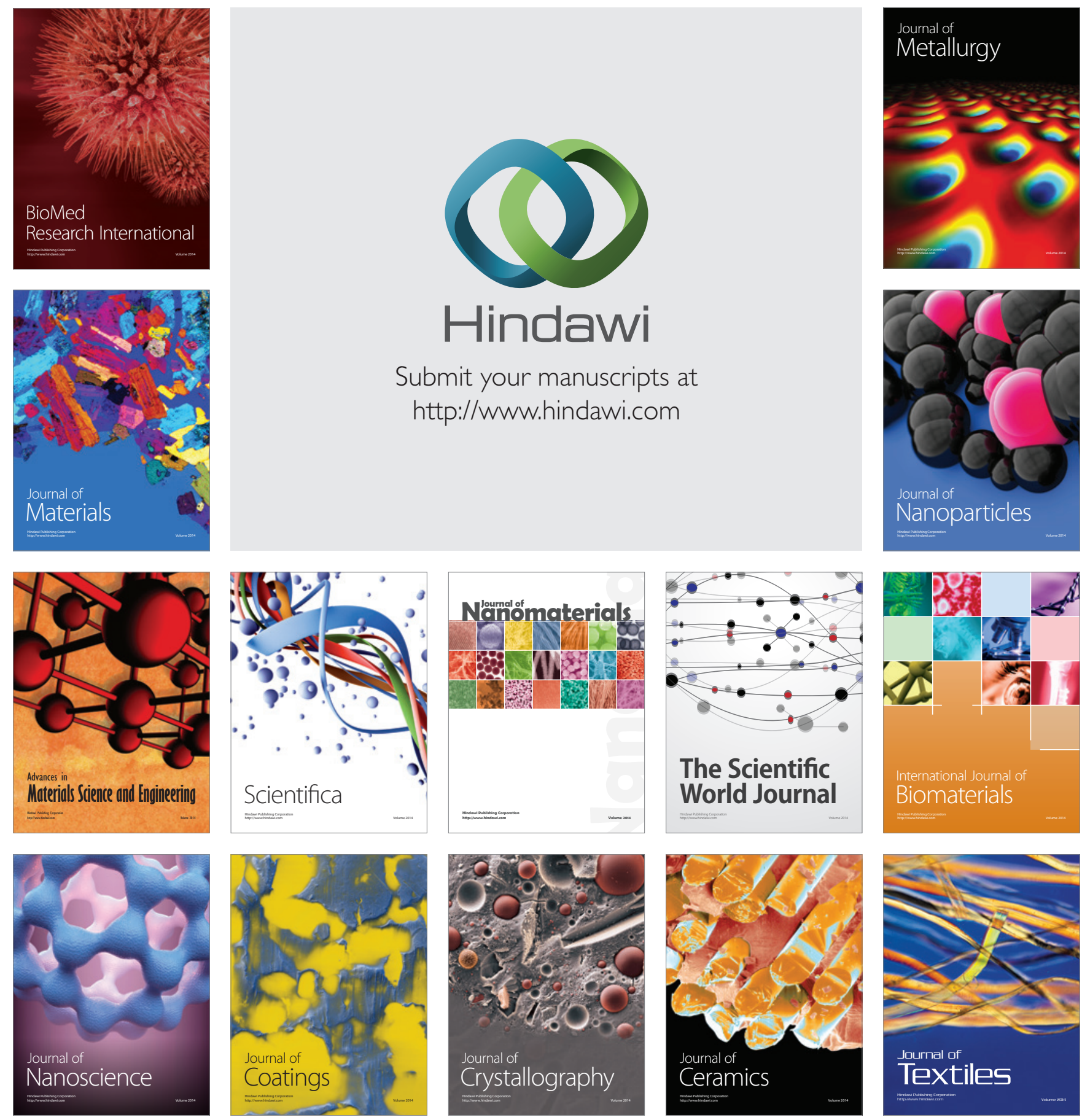